\title{
REDUCTION OF HIPPOCAMPAL CELL DEATH AND PROTEOLYTIC RESPONSES IN TISSUE PLASMINOGEN ACTIVATOR KNOCKOUT MICE AFTER TRANSIENT GLOBAL CEREBRAL ISCHEMIA
}

\author{
S.-R. LEE, , , b J. LOK, ${ }^{a, c}$ A. ROSELL, ${ }^{a}$ H.-Y. KIM, ${ }^{a}$ \\ Y. MURATA, ${ }^{a}$ D. ATOCHIN, ${ }^{d}$ P. L. HUANG, ${ }^{d}$ X. WANG, ${ }^{a}$ \\ C. AYATA, ${ }^{e}$ M. A. MOSKOWITZ ${ }^{\mathrm{e}}$ AND E. H. LO ${ }^{\mathrm{a} *}$ \\ ${ }^{a}$ Neuroprotection Research Laboratory, Departments of Radiology \\ and Neurology, Massachusetts General Hospital, and Program in \\ Neuroscience, Harvard Medical School, Boston, MA 02129, USA \\ ${ }^{b}$ Department of Pharmacology, School of Medicine, Keimyung Univer- \\ sity, Daegu, Korea \\ 'Division of Pediatric Critical Care Medicine, Massachusetts General \\ Hospital, Boston, MA 02129, USA \\ ${ }^{d}$ Cardiovascular Research Center, Massachusetts General Hospital, \\ Harvard Medical School, Boston, MA 02129, USA \\ e Stroke and Neurovascular Regulation Center, Massachusetts Gen- \\ eral Hospital, Harvard Medical School, Boston, MA 02129, USA
}

\begin{abstract}
Knockout mice deficient in tissue plasminogen activator (tPA) are protected against hippocampal excitotoxicity. But it is unknown whether similar neuroprotection occurs after transient global cerebral ischemia, which is known to selectively affect the hippocampus. In this study, we tested the hypothesis that hippocampal cell death in tPA knockout mice would be reduced after transient global cerebral ischemia, and this neuroprotection would occur concomitantly with amelioration of both intra- and extracellular proteolytic cascades. Wild-type and tPA knockout mice were subjected to $20 \mathrm{~min}$ of transient bilateral occlusions of the common carotid arteries. Three days later, Nissl and terminal deoxynucleotidyl transferase biotin-dUTP nick end labeling staining demonstrated that hippocampal cell death was significantly reduced in tPA knockout brains compared with wildtype brains. Caspase- 3 and the two major brain gelatinases (matrix metalloproteinase (MMP)-9 and MMP-2) were assessed as representative measurements of intra- and extracellular proteolysis. Post-ischemic levels of caspase-3, MMP-9 and MMP-2 were similarly reduced in tPA knockouts compared with wild-type hippocampi. Taken together, these data suggest that endogenous tPA contributes to hippocampal injury after cerebral ischemia, and these pathophysiologic pathways may involve links to aberrant activation of caspases and MMPs. ( 2007 IBRO. Published by Elsevier Ltd. All rights reserved.
\end{abstract}

Key words: excitotoxicity, anoikis, neuron, caspase, matrix metalloproteinase.

${ }^{*}$ Correspondence to: E. H. Lo, Neuroprotection Research Laboratory, MGH East 149-2401, 13th Street, Charlestown, MA, USA. Tel: +1617-726-4043; fax: +1-617-726-7830.

E-mail address: Lo@helix.mgh.harvard.edu (E. H. Lo).

Abbreviations: KO, knockout; MMP, matrix metalloproteinases; tPA, tissue plasminogen activator; TUNEL, terminal deoxynucleotidyl transferase biotin-dUTP nick end labeling; WT, wild-type.
The hippocampus is selectively vulnerable to injury and cell death after transient global cerebral ischemia (Kirino, 1982; Pulsinelli et al., 1982). Multiple mechanisms have been proposed to explain this phenomenon, including pathways of excitotoxicity, apoptosis, oxidative stress and neuroinflammation (Kirino, 2000).

One specific mediator that has been implicated in hippocampal degeneration is tissue plasminogen activator (tPA). Whereas tPA plays a well-established role in blood as a fibrinolytic factor, tPA is now recognized to also play unique roles as a neuromodulator in brain. tPA can be released by neurons in a calcium-dependent manner (Gualadris et al., 1996). tPA is essential for cerebellar development and learning (Seeds et al., 1990, 1995). And tPA and its associated plasminogen proteases have been shown to participate in extracellular proteolysis and tissue remodelling in the brain, especially within the hippocampus (Wu et al., 2000). tPA knockout (KO) mice demonstrate alterations in long term potentiation (Baranes et al., 1998) whereas transgenic mice overexpressing tPA show enhanced long term potentiation (Madani et al., 1999). Some of these processes may be relevant to pathology. Neurons cultured from tPA KO mice are protected against hypoxia and oxidative stress (Nagai et al., 2001). Hippocampi in tPA KO mice are resistant to kainic acid injections, seizureinduced injury, and stress-induced neurodegeneration (Tsirka et al., 1995, 1996; Pawlak et al., 2005).

Many of these cellular mechanisms may be activated in the pathophysiology of ischemic brain injury as well. Therefore, in the present study, we tested the hypothesis that IPA KO mice would be protected against global cerebral ischemia. Because there are many connections between the plasminogen system and other protease systems in brain (Lo et al., 2002), we also assessed the effects of tPA gene $\mathrm{KO}$ on the ischemic response of intraand extra-cellular proteases such as caspases and matrix metalloproteinases (MMPs) respectively.

\section{EXPERIMENTAL PROCEDURES}

\section{Transient global cerebral ischemia}

All experiments were performed following an institutionally approved protocol in accordance with The National Institutes of Health Guide for the Care and Use of Laboratory Animals. The study was performed with the assurance that a minimal number of animals was used and the experimental procedures did not significantly cause animal suffering. Three- to 4-month-old male tPA KO mice and their corresponding wild-type (WT) littermates from the C57BI6 background were subjected to transient global cerebral ischemia, following standard techniques whereby cerebral 
perfusion drops below 15\% after arterial occlusion (Lee et al., 2004). General anesthesia was maintained with $1 \%$ isoflurane via facemask. Body temperature was monitored and maintained at $36.5-37.5^{\circ} \mathrm{C}$ with a feedback heating pad. Both common carotid arteries were carefully isolated from the adjacent vagus nerve and occluded for 20 min with micro-clips. To reperfuse, clips were removed and patency of arteries was confirmed by inspection.

\section{Analysis of hippocampal injury}

Evaluation of histological damage was performed in a blinded manner on brain sections stained with $0.1 \%$ Cresyl Violet according to the Nissl method. Viable neurons were defined as neurons in which a clear nucleus could be seen. With Nissl staining, ischemic damaged neurons exhibit features including pyknosis and shrunken cell bodies. Hippocampal neuronal damage was evaluated using a standard semi-quantitative scale (Kawase et al., 1999): briefly, grade 0, no damage to any hippocampal subregion; grade 1 , scattered ischemic neurons in CA1 subregion; grade 2, moderate ischemic damage in CA1 subregion (less than half of pyramidal cells affected); grade 3 , severe damage to pyramidal cells in CA1 subregion (more than half of pyramidal cells affected); grade 4 , extensive cell damage in all hippocampal subregions. Note that the grading scale ultimately included all sectors of the hippocampus because although the CA1 area is most well known as being selectively vulnerable in rats, it has also been previously shown that the CA2 "corner" is also damaged in mouse models of transient global cerebral ischemia (Yang et al., 2000; Cho et al., 2007). The nonparametric Mann-Whitney test was used to compare WT vs. KO brains. $P<0.05$ was considered significant.

\section{Gelatin zymography}

The brains were removed quickly, and the hippocampus was dissected. Brain tissue were prepared for either in situ or homogenate gel zymography as described previously (Lee et al., 2004). For in situ preparations, brains were removed after transcardial perfusion with ice-cold PBS ( $\mathrm{pH}$ 7.4), and quickly frozen in 2-methylbutane with liquid nitrogen. Sections $(20 \mu \mathrm{m})$ were cut on a cryostat and incubated in $0.05 \mathrm{M}$ Tris- $\mathrm{HCl}, 0.15 \mathrm{M} \mathrm{NaCl}, 5 \mathrm{mM}$ $\mathrm{CaCl}_{2}$, and $0.2 \mathrm{mM} \mathrm{NaN}, \mathrm{pH} 7.6$, containing $40 \mu \mathrm{g}$ of FITClabeled gelatin (Molecular Probes, Eugene, OR, USA), at room temperature during overnight. The gelatin with a fluorescent tag remains caged (no fluorescence) until the gelatin is cleaved by gelatinase activity. Note that this method detects regionally specific gelatinolytic activity but does not distinguish between MMP-9 and MMP-2. For homogenates, lysis buffer including protease inhibitors was used on ice. After centrifugation, supernatant was collected, and total protein concentrations were determined using the Bradford assay (Bio-Rad, Hercules, CA, USA). Prepared protein samples were loaded and separated by $10 \%$ Tris-glycine gel with $0.1 \%$ gelatin as substrate. After separation by electrophoresis, the gel was renatured and then incubated with developing buffer at $37{ }^{\circ} \mathrm{C}$ for $40 \mathrm{~h}$ as described previously (Asahi et al., $2001 \mathrm{~b}$ ). After developing, the gel was stained with $0.5 \%$ Coomassie Blue R-250 for $2 \mathrm{~h}$ and then distained appropriately. In all gels human MMP-2 standard (Chemicon, Temecula, CA, USA) and murine MMP-9 standards were used as internal quantitation markers. Gel to gel variations are unavoidable. But since we load an equal amount of MMP standard in each gel, the band intensity for the standards may be different between different gels but should represent the same amount of MMP protein standard. Therefore we can normalize band intensities between different gels by calculating everything as a ratio of the exact same amount of loaded MMP standards. All bands were quantified using ImageJ and integrated band intensities expressed as a percentage to MMP-9 standards. Means were calculated per each group and data analyzed using ANOVA followed by the post hoc Tukey-Kramer test. $P<0.05$ was considered significant.

\section{Immunohistochemistry}

Double-label immunohistochemistry was performed to assess the distribution of MMP-9 following previously published methods (Lee et al., 2004). Anesthetized animals were perfused transcardially with ice-cold PBS, $\mathrm{pH} 7.4$, followed with ice-cold $4 \%$ paraformaldehyde in PBS, $\mathrm{pH}$ 7.4. The brains were removed, immersed with the same fixative overnight at $4{ }^{\circ} \mathrm{C}$, and cryoprotected in 15 and $30 \%$ sucrose solutions in PBS at $4{ }^{\circ} \mathrm{C}$. Frozen coronal sections $(20 \mu \mathrm{m}$ thick) were prepared using a cryostat. After blocking with PBS containing $0.2 \%$ Triton X-100 and $3 \%$ normal goat serum, sections were incubated overnight at $4{ }^{\circ} \mathrm{C}$ with the MMP-9 rabbit polyclonal antibody (1:200; a kind gift from Dr. Robert Senior, Washington University, St. Louis, MO, USA) in combination with anti-NeuN monoclonal antibody (1:100; Chemicon) or anti-GFAP antibody (1:200; Chemicon) in PBS 0.2\% Triton $X-100$ and $2 \%$ normal goat serum. Caspase activation was assessed using an activated caspase- 3 antibody (1:200, Cell Signaling Technology, Beverly, MA, USA). The sections were washed with PBS then incubated with secondary antibodies for 30 min. Negative control sections were not exposed to primary antibodies.

\section{Terminal deoxynucleotidyl transferase biotin-dUTP nick end labeling (TUNEL) staining}

TUNEL staining was performed by using an in situ cell death detection kit (Roche Molecular Biochemicals, Mannheim, Germany). Nuclei of tissue sections were stripped of proteins by incubation with proteinase $\mathrm{K}(20 \mu \mathrm{g} / \mathrm{ml}$ in $10 \mathrm{mM}$ Tris $-\mathrm{HCl}$, at $37^{\circ} \mathrm{C}$ ) for $15 \mathrm{~min}$. The slices were then washed in distilled water and PBS and incubated in $0.3 \%$ hydrogen peroxide. After equilibration, each section was incubated with $50 \mu$ l of TUNEL reaction mixture including terminal deoxynucleotidyl transferase for $60 \mathrm{~min}$ at $37^{\circ} \mathrm{C}$ in humidified condition. Detection of double strand breaks in genomic DNA was performed with 2,3'-diaminobenzidine tetrahydrochloride (DAB) $(0.5 \mathrm{mg} / \mathrm{ml}$ in $50 \mathrm{mmol} / \mathrm{L}$ Tris- $\mathrm{HCl}$ buffer, $\mathrm{pH}$ 7.4) as a substrate for the peroxidase. TUNEL-positive cells were detected by observation of dark-brown staining nuclei in the tissue section.

\section{RESULTS}

As expected, delayed neuronal death occurs over the course of several days after transient global cerebral ischemia. In our mouse models, Nissl staining of excised brain at 3 days post-ischemia showed that pyramidal neurons of the hippocampus were selectively damaged, with most of the injury occurring in the medial CA1 sector and in severe cases, including the CA2 "corner" as well (Fig. 1). Compared with WT brains, neuronal injury in tPA KO brains was significantly reduced (Fig. 1). TUNEL staining confirmed the presence of DNA damage within CA1 regions, indicative of cell death in WT hippocampi (Fig. 2).

Because TUNEL-positive markers have been associated with caspase-mediated cell death, we next examined hippocampal caspase levels in our model. Caspase- 3 was assessed as a representative marker of intracellular proteolysis. In areas corresponding to CA1 neuronal death in WT brains, caspase- 3 positive cells were observed (Fig. 3). Within the limits of our immunostaining sensitivity, no clear caspase-3 signal was detected in tPA KO hippocampi, suggesting that it was markedly reduced compared with the ischemic responses in WT brain samples. 


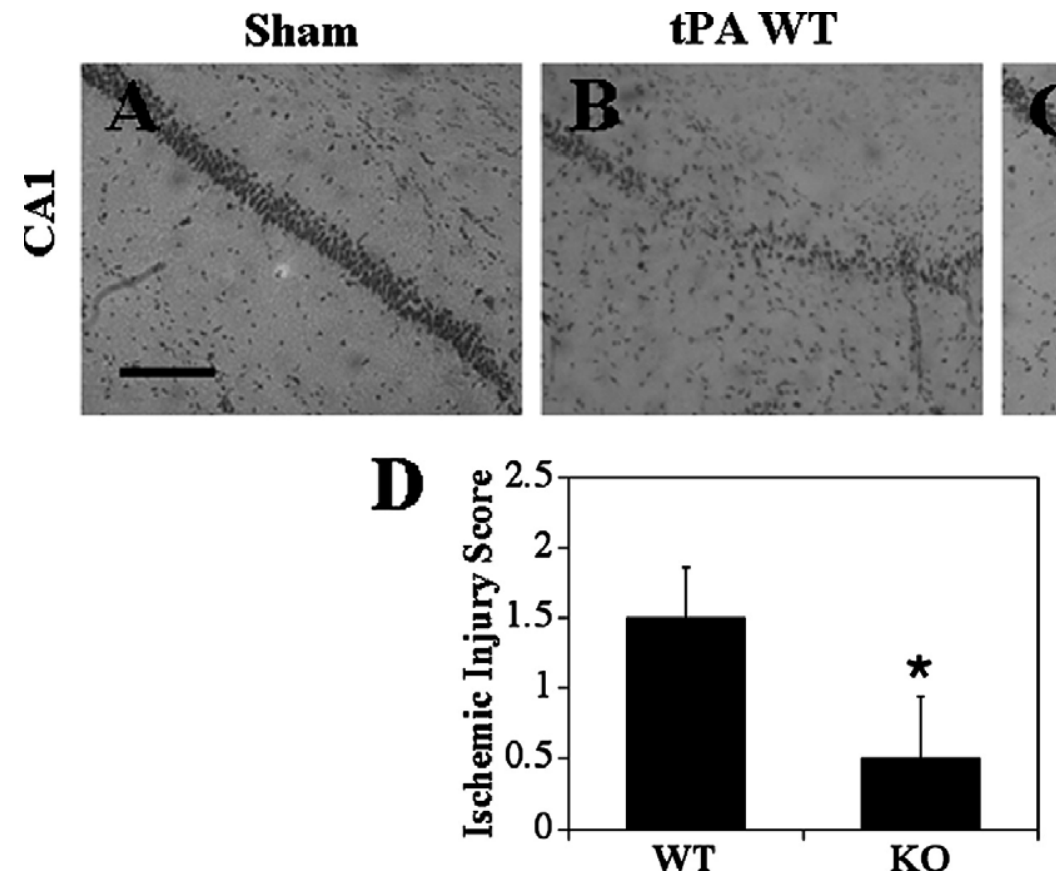

Fig. 1. Nissl staining and neuronal cell death in the CA1 sub-region. (A) Neuronal staining in the normal sham-operated hippocampus. (B) WT ischemic mice exhibit a severe loss of CA1 hippocampal neurons. (C) Reduced CA1 neuronal death in the tPA KO ischemic mice. (D) Semiquantitative analysis (mean \pm S.E.M.) showing a significant reduction of hippocampal neuronal death in tPA KO mice when compared with WT after global transient ischemia. Scale bar $=100 \mu \mathrm{m}$; * $P<0.05$; sham group, $n=3$; WT and KO ischemic groups, $n=6$ each.

In addition to intracellular proteolysis, extracellular matrix proteolysis has also been recognized as an important pathogenic mechanism in neuronal injury. Therefore, inducible MMP-9 was assessed as a representative marker of extracellular matrix degradation. Immunostaining confirmed the presence of MMP-9 positive cells in areas of CA1 hippocampal damage. MMP-9 signals appeared to co-localize with both GFAP and NeuN positive cells, suggesting that both glial as well as neuronal elements were involved (Fig. 4). To confirm that these MMP protein levels were active, in situ zymography was additionally performed. In situ gelatinase activity was upregulated in all ischemic CA1 regions of the hippocampus, but enzyme activity appeared to be more pronounced in WT brains compared with tPA KO brains (Fig. 5). Finally, to quantify these MMP responses, gelatin zymography was performed on hippocampal homogenates. A clear upregulation of the major brain gelatinases MMP-9 and MMP-2 was detected in the hippocampus at 3 days after transient global cerebral ischemia (Fig. 6). Densitometry showed that both MMP-9 and MMP-2 responses were significantly reduced in TPA KO hippocampal tissue compared with WT tissue (Fig. 6).

\section{DISCUSSION}

Experimental findings suggest that besides acting as a fibrinolytic agent in blood, tPA might also play an important role in brain. tPA may interact with the NMDA receptor complex, thus amplifying deleterious excitotoxic currents after brain injury (Nicole et al., 2001). tPA may also act in a cytokine-like fashion and mediate microglial activation thus contributing to neuroinflammation (Gravanis and Tsirka, 2005). The potential neurotoxic effects of tPA have been especially well characterized in mutant mouse models. KO mice lacking tPA show smaller infarcts in the cortex (Wang et al., 1998) and reduced blood-brain barrier injury (Tsuji et al., 2005) after focal cerebral ischemia. The critical role for excitotoxicity has been confirmed because tPA KO mice are protected against direct NMDA or kainate injections into the hippocampus (Tsirka, 2002). Surprisingly, however, tPA KO mice had never been examined as to whether their hippocampi were directly resistant to cerebral ischemia. In the present study, we demonstrated that genetic KO of tPA indeed protected CA1 neurons in the hippocampus from delayed death after transient global cerebral ischemia, and that some of this neuroprotection may be associated with reductions in potentially damaging protease cascades. In particular, elevations in caspase- 3 and MMP-9 during the delayed ischemic progression of hippocampal injury were significantly ameliorated by deleting endogenous tPA.

The involvement of a form of programmed cell death in the hippocampus after transient global cerebral ischemia has been studied for some time. Many pathogenic mechanisms have been proposed to explain this neurobiological mystery (Kirino, 2000). The involvement of apoptotic-like programs was demonstrated by the seminal finding of Chen et al. (1998), who showed that caspases were upregulated during the delayed progression of CA1 neuronal death. The central importance of intracellular proteases has been supported by other studies showing that inhibition of calpains and cathepsins decreases ischemic brain 
Hippocampus

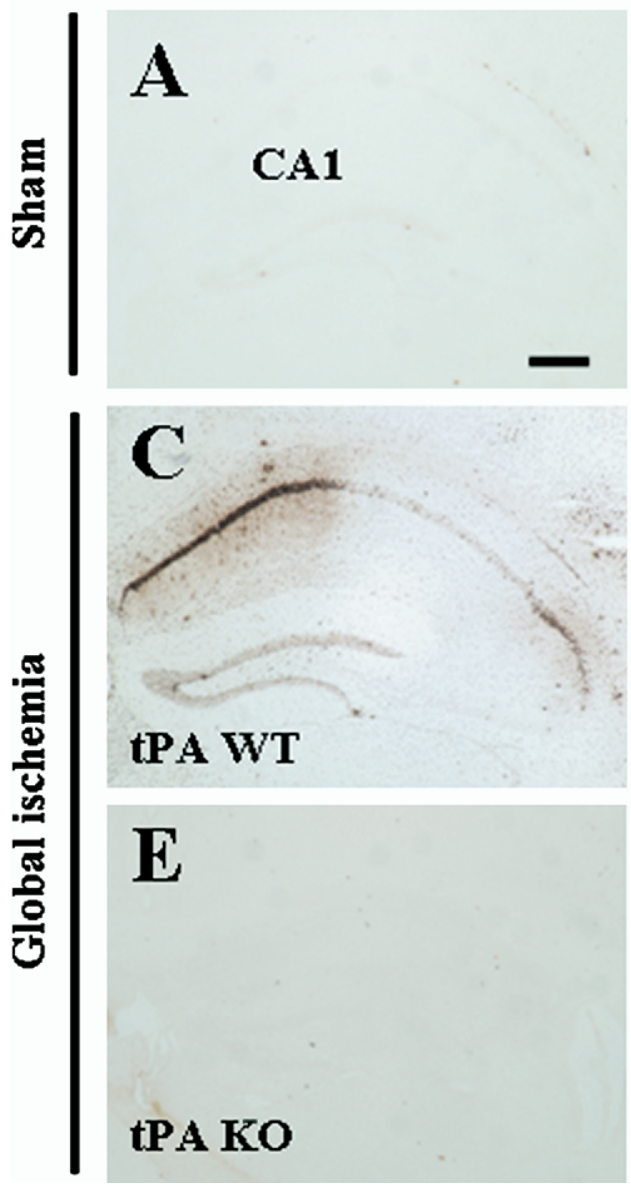

CA1
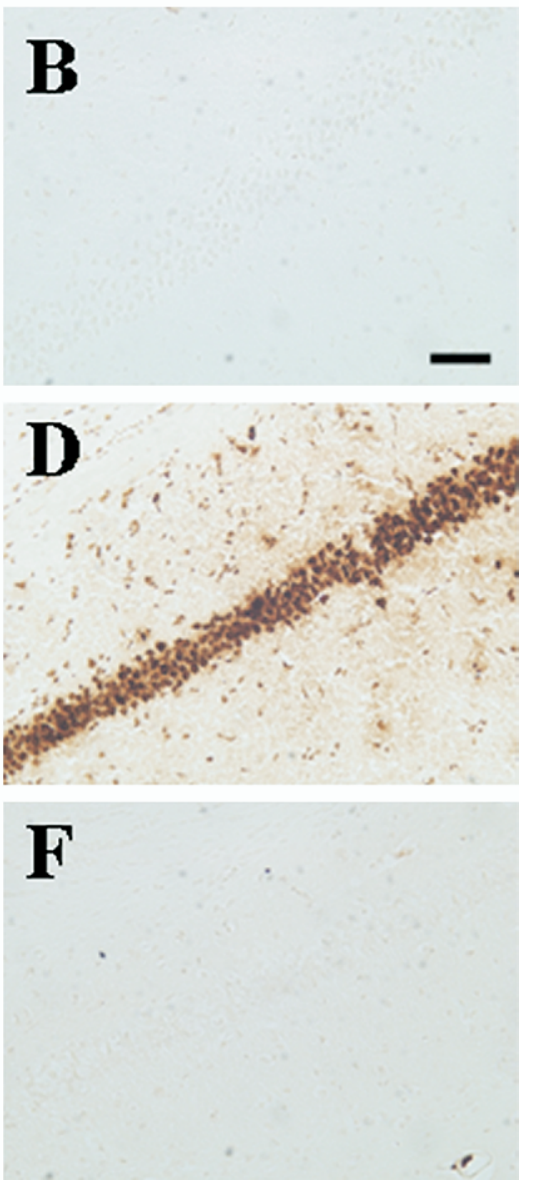

Fig. 2. TUNEL staining. No significant TUNEL positive cells were found in the hippocampus of control mice (A, B). In WT ischemic mice, TUNEL positive cells were significantly increased in the CA1 sector and in this severe case, the CA2 "corner" of the hippocampus as well (C, D). Markedly less TUNEL signals were noted in the ischemic tPA KO mice (E, F). Scale bars $=300 \mu \mathrm{m}$ in (A) and $50 \mu \mathrm{m}$ in (B).

injury and neurodegeneration (Yamashima, 2000; Ray and Banik, 2003). More recently, extracellular proteases such as MMPs have also been shown to play key roles. It is worth noting that both MMP-2 and MMP-9 were affected by tPA gene deletion in our model. We previously showed that $\mathrm{KO}$ mice lacking MMP-9 were protected against both focal and global cerebral ischemia (Asahi et al., 2000, 2001b;
Lee et al., 2004) whereas MMP-2 KOs were not protected against focal ischemia (Asahi et al., 2001a). Which protease plays a more dominant role in the present tPA KO system remains to be fully dissected. Nevertheless, our overall data here are consistent with these general concepts, and suggest that the tPA protease cascade may somehow be linked to aberrant induction of both caspases
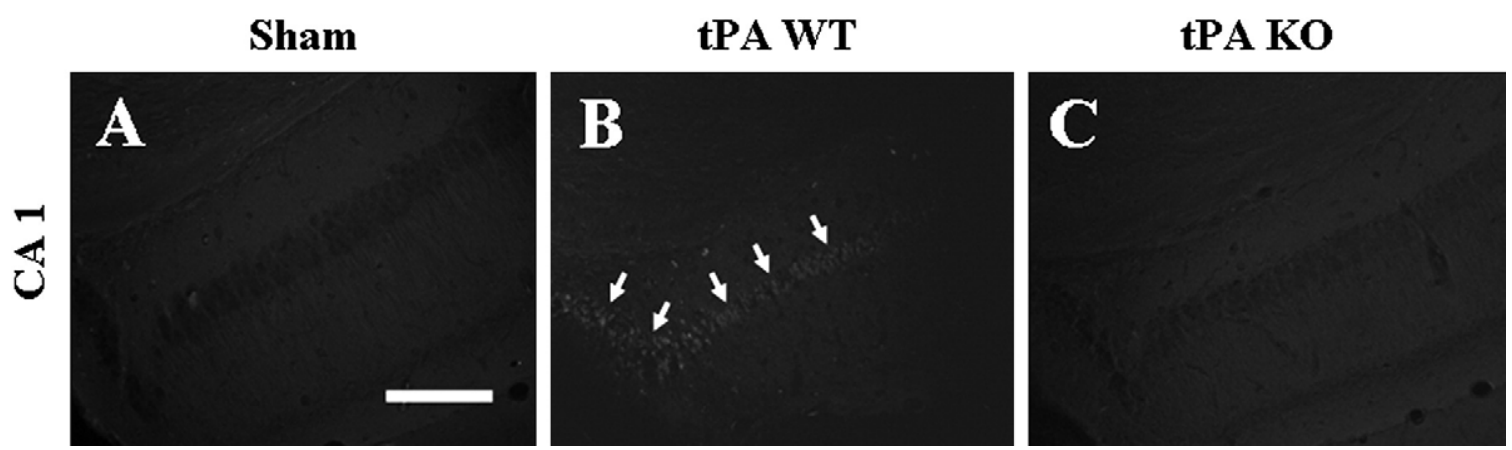

Fig. 3. Caspase-3 immunohistochemistry. (A) No caspase- 3 was detected in the sham group while caspase- 3 signals (arrows) were detected in CA1 cells of the WT ischemic mice (B). In the tPA KO mice hippocampus, no caspase-3 staining was detected (C). Scale bar=50 $\mu \mathrm{m}$. 

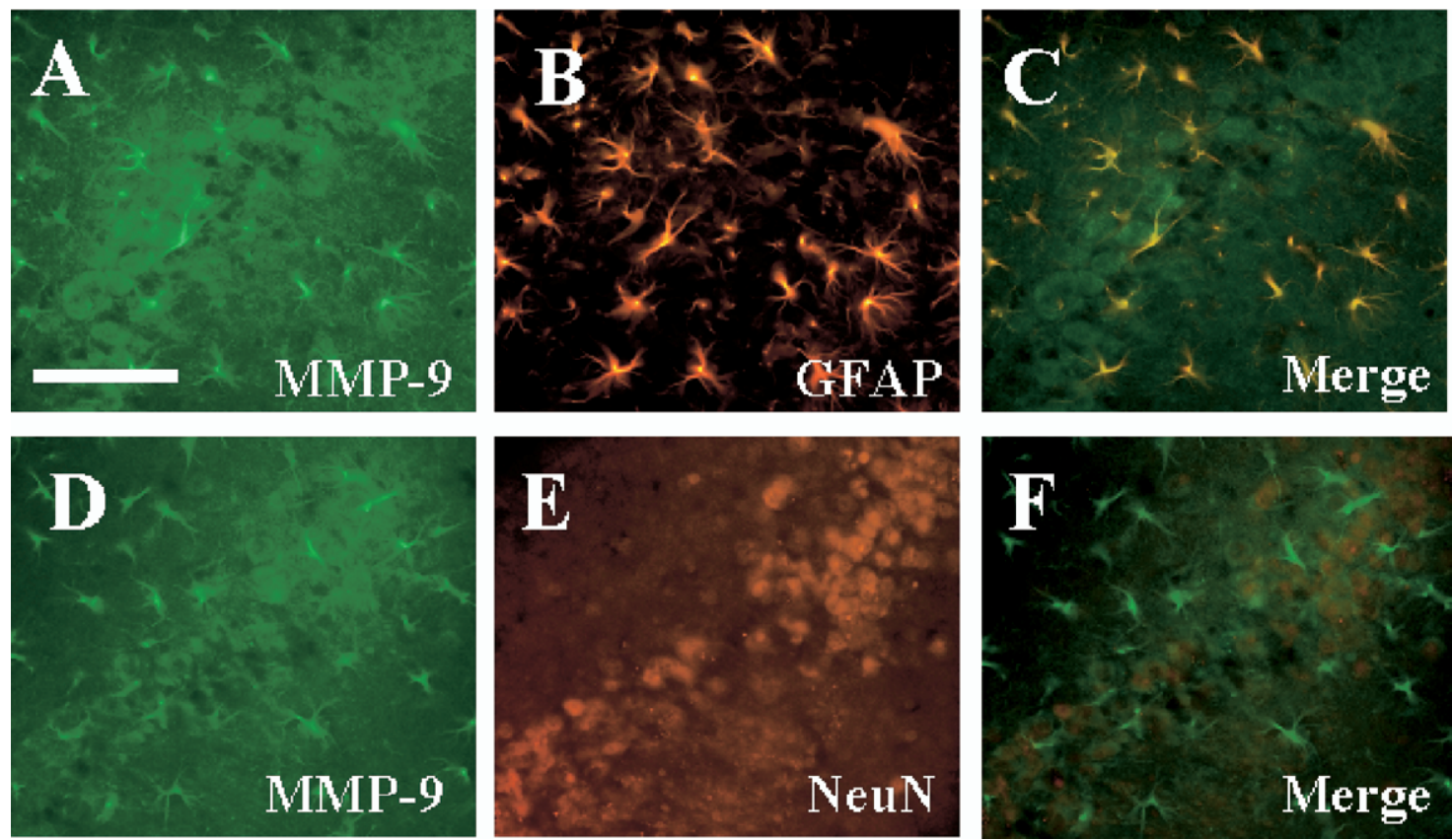

Fig. 4. MMP-9 immunohistochemistry showing co-localization of MMP-9 (A, D) with GFAP and NeuN reactive cells (B and $E$, respectively), indicating that MMP-9 is expressed by activated astrocytes and neurons $(C, F)$ in the CA1 sub-region. Scale bar $=50 \mu \mathrm{m}$.

and MMPs. Others have suggested that tPA and associated activation of plasmin can degrade interneuronal matrix such as laminin and thus trigger caspase activation in an anoikis-like manner (Chen and Strickland, 1997). Similarly, previous studies have suggested that by binding
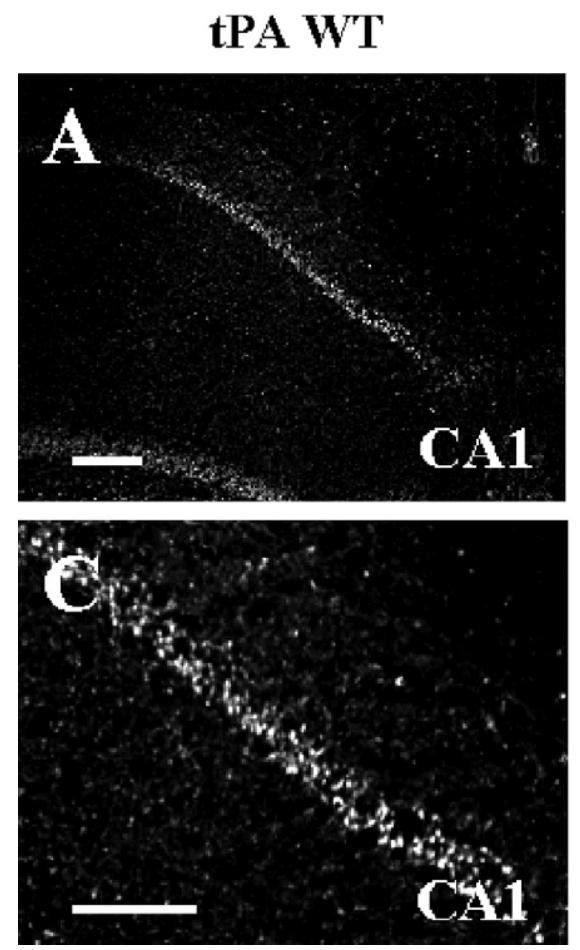

onto lipoprotein receptors, tPA can upregulate MMPs during cerebral ischemia (Wang et al., 2003). Altogether, the true mechanisms underlying delayed ischemic cell death in hippocampus will be complex and multifactorial. Nevertheless, our data here suggest an important role for tPA,

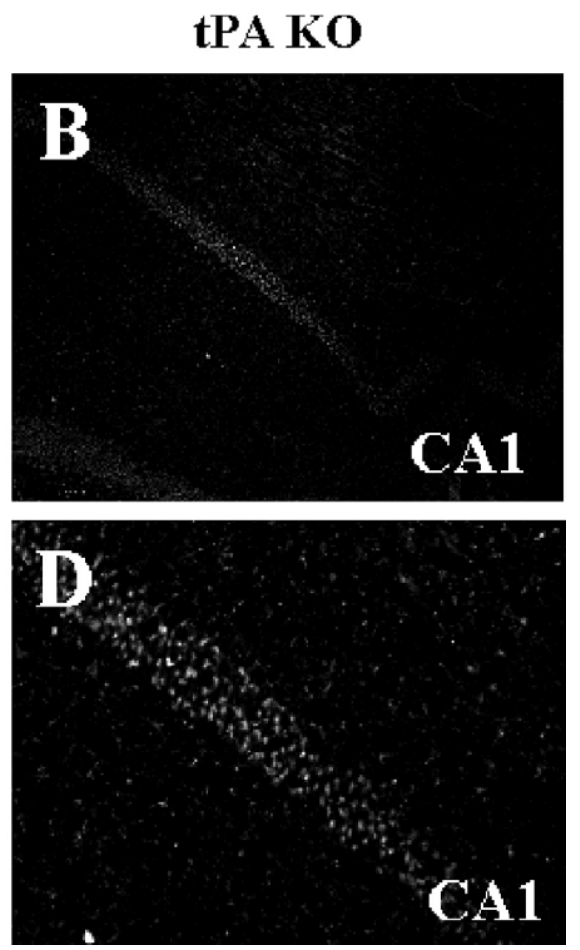

Fig. 5. In situ zymography showing increased gelatinase activity in WT mice in the CA1 sub-region after ischemia (A, C) compared with tPA KO mice $(B, D)$. Scale bars $=200 \mu \mathrm{m}(\mathrm{A}), 100 \mu \mathrm{m}(\mathrm{C})$. 


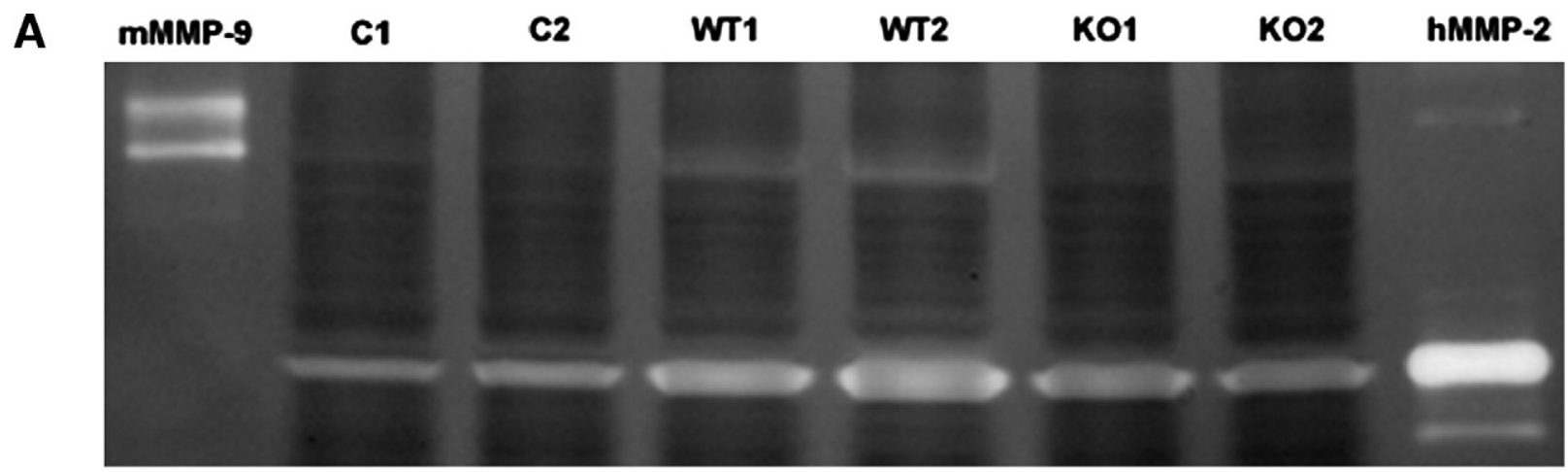

B
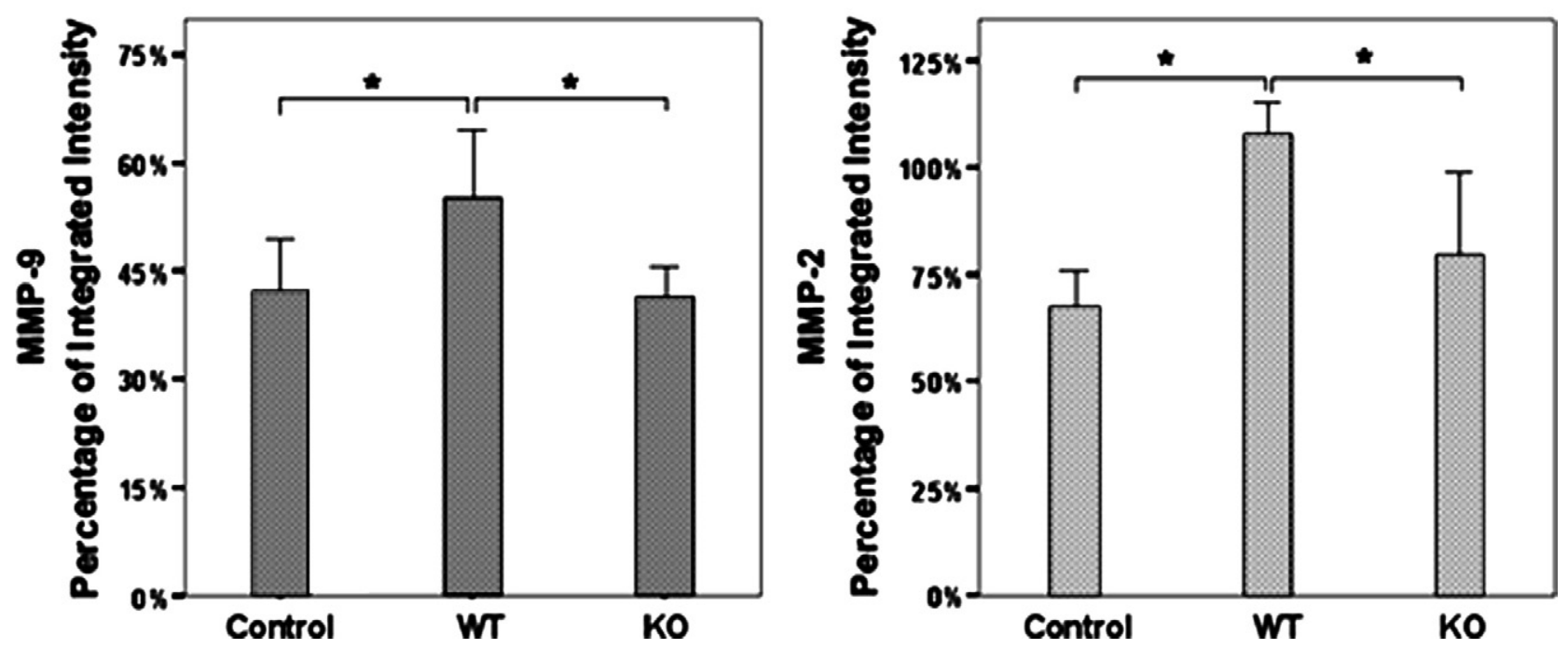

Fig. 6. Gel zymography. (A) Representative zymogram displaying MMP-9 and MMP-2 levels. (B) Ischemic WT mice (WT1 and WT2) demonstrate significantly increased MMP-9 and MMP-2 levels compared than non-ischemic controls (C1 and C2) and ischemic tPA KO mice (KO1 and KO2). Note: mMMP-9 and hMMP-2 represent lanes loaded with murine MMP-9 (105 kDa and $97 \mathrm{kDa}$ for assumed pro- and active forms respectively) and human MMP-2 (same $72 \mathrm{kDa}$ MW as mouse MMP-2) standards respectively. Band intensities (mean \pm S.E.M.) are expressed as percentage of the loaded MMP standards, * $P<0.05$; normal controls, $n=4$; WT and KO ischemic groups, $n=5$ each.

perhaps as a candidate upstream trigger in the progression of intracellular and extracellular proteolysis.

Our primary finding that tPA KO mice were protected against global cerebral ischemia is generally consistent with previous studies demonstrating similar protection against focal cerebral ischemia and stereotactic injections of excitotoxins (Tsirka et al., 1995, 1996; Wang et al., 1998). However, important differences should be noted in models involving exogenous infusions of tPA. In contrast to these data in mutant mice, we (Meng et al., 1999) and others (Klein et al., 1999) have failed to find that i.v. treatment with recombinant tPA had any exacerbating effect on neuronal death in rat models of focal and global cerebral ischemia. These differences are not easy to explain. Ultimately, it may be related to levels of tPA in blood versus brain. Endogenous tPA expression in ischemic neurons per se may evoke very different responses compared with exogenous administration of tPA into vascular compartments with possibly lower penetrance into brain.

Our present data may be clinically significant because tPA remains the only FDA-approved treatment for acute ischemic stroke. When ischemia is caused by occlusive clots, thrombolysis with tPA has been shown to be clinically effective. However, many caveats remain, and tPA use remains restricted to less than $5 \%$ of all stroke patients. Even in properly treated patients, clinical improvements after IPA may be sometimes modest, and there is a noted elevation in risks of blood-brain barrier damage, edema and cerebral hemorrhage (Kaur et al., 2004). It remains to be determined whether these connections between tPA and excitotoxicity, microglial inflammation, and protease imbalances described here and by others in experimental model systems may truly explain some of our clinical experiences.

Taken together, our findings suggest that besides amplifying excitotoxicity and activating microglia, tPA may also contribute to hippocampal injury after cerebral ischemia via intra- and extracellular protease cascades. But there are several important caveats in our study. First, it is difficult to unequivocally prove causality. It is possible that the reductions in caspase and MMPs may be nonspecific and simply due to decreased overall injury in the hip- 
pocampus. In order to truly establish causality, pharmacologic rescue or genetic reconstitution experiments would have to be carried out. Second, we do not truly know how the intra- versus extracellular protease cascades are connected. It is attractive to speculate that consistent with other studies (Chen and Strickland, 1997; Gu et al., 2002), extracellular proteolysis disrupted cell-matrix homeostasis and secondarily induced caspase activation in an anoikislike manner. But others have also demonstrated that inhibition of intracellular proteases such as cathepsins and calpains can secondarily suppress MMPs after cerebral ischemia (Tsubokawa et al., 2006). Further in-depth timecourse studies would be required to dissect this issue in our model. Finally, our data mainly focused on proteases and we do not understand what substrates are involved. Within the cell, many caspase targets have been described that contribute to cell death, but what extracellular substrates are critical for the MMP pathology here remains to be defined.

Transient global cerebral ischemia is a major cause of brain injury. A stereotyped response has been described whereby pyramidal neurons in the select sectors of the hippocampus undergo delayed cell death 2-5 days after the initial insult (Kirino, 2000; Yang et al., 2000; Cho et al., 2007). Many different cellular mechanisms have been implicated in this delayed neuronal death phenomenon, including excitotoxicity, oxidative injury, and apoptotic-like programmed cell death pathways. However, the precise molecular mediators involved in this selective neuronal death in hippocampus remains to be definitively elucidated. Our study demonstrates a central role of endogenous tPA. By deleting the tPA gene, hippocampal injury was reduced in concert with a broad amelioration of both intra- and extracellular protease imbalances. Further studies are warranted to investigate whether the tPAcaspase-MMP protease response cascade might be exploited as a potential therapeutic target for cerebral ischemia.

Acknowledgments-Supported in part by a Bugher award from the American Heart Association and NIH grants R01-NS37074, R01-NS40529, R01-NS48422, R01-NS56458 and P50-NS10828. Anna Rosell is the recipient of a post-doctoral grant from Ministerio de Educacion y Ciencia (EX2006/766).

\section{REFERENCES}

Asahi M, Asahi K, Jung JC, del Zoppo GJ, Fini ME, Lo EH (2000) Role of matrix metalloproteinase 9 in focal cerebral ischemia: effects of gene knockout and enzyme inhibition with BB-94. J Cereb Blood Flow Metab 20:1681-1690.

Asahi M, Sumii T, Fini ME, Itohara S, Lo EH (2001a) Matrix metalloproteinase 2 gene knockout has no effect on acute brain injury after focal ischemia. Neuroreport 12:3003-3007.

Asahi M, Wang X, Mori T, Sumii T, Jung J, Moskowitz MA, Fini ME, Lo $\mathrm{EH}$ (2001b) Effects of matrix metalloproteinase 9 gene knockout on the proteolysis of blood-brain barrier and white matter components after cerebral ischemia. J Neurosci 21:7724-7732.

Baranes D, Lederfein D, Huang YY, Chen M, Bailey C, Kandel E (1998) Tissue plasminogen activator contributes to the late phase of LTP and to synaptic growth in the hippocampal mossy fiber pathway. Neuron 21:813-825.
Chen J, Nagayama T, Jin K, Stetler RA, Zhu RL, Graham SH, Simon RP (1998) Induction of caspase-3-like protease may mediate delayed neuronal death in the hippocampus after transient cerebral ischemia. J Neurosci 18:4914-4928.

Chen ZL, Strickland S (1997) Neuronal death in the hippocampus is promoted by plasmin-catalyzed degradation of laminin. Cell 91: 917-925.

Cho KO, Kim SK, Cho YJ, Sung KW, Kim SY (2007) Regional differences in the neuroprotective effect of minocycline in a mouse model of global forebrain ischemia. Life Sci 80:2030-2035.

Gravanis I, Tsirka SE (2005) Tissue plasminogen activator and glial function. Glia 49:177-183.

Gu Z, Kaul M, Yan B, Kridel SJ, Cui J, Strongin A, Smith JW, Liddington RC, Lipton SA (2002) S-nitrosylation of matrix metalloproteinases: signaling pathway to neuronal cell death. Science 297:1186-1190.

Gualadris A, Jones TE, Strickland S, Tsirka SE (1996) Membrane depolarization induces calcium dependent secretion of tissue plasminogen activator. J Neurosci 16:2220-2225.

Kaur J, Zhao Z, Klein GM, Lo EH, Buchan AM (2004) The neurotoxicity of tissue plasminogen activator? J Cereb Blood Flow Metab 24:945-963.

Kawase M, Murakami K, Fujimura M, Morita-Fujimura Y, Gasche Y, Kondo T, Scott RW, Chan PH (1999) Exacerbation of delayed cell injury after transient global ischemia in mutant mice with CuZn superoxide dismutase deficiency. Stroke 30:1962-1968.

Kirino T (1982) Delayed neuronal death in the gerbil hippocampus following ischemia. Brain Res 239:57-69.

Kirino T (2000) Delayed neuronal death. Neuropathology 20 (Suppl): S95-S97.

Klein GM, Li H, Sun P, Buchan AM (1999) Tissue plasminogen activator does not increase neuronal damage in rat models of global and focal ischemia. Neurology 22:1381-1384.

Lee SR, Tsuji K, Lee S, Lo EH (2004) Role of matrix metalloproteinases in delayed neuronal damage after transient global cerebral ischemia. J Neurosci 24:671-678.

Lo EH, Wang X, Cuzner ML (2002) Extracellular proteolysis in brain injury and inflammation: role for plasminogen activators and matrix metalloproteinases. J Neurosci Res 69:1-9.

Madani R, Hulo S, Toni N, Madani H, Steimer T, Muller D, Vassalli JD (1999) Enhanced hippocampal long-term potentiation and learning by increased neuronal expression of tissue-type plasminogen activator in transgenic mice. EMBO J 18:3007-3012.

Meng W, Wang X, Asahi M, Kano T, Asahi K, Ackerman RH, Lo EH (1999) Effects of tissue type plasminogen activator in embolic versus mechanical models of focal cerebral ischemia in rats. J Cereb Blood Flow Metab 19:1316-1322.

Nagai N, Yamamoto S, Tsuboi T, Ihara H, Urano T, Takada Y, Terakawa S, Takada A (2001) Tissue type plasminogen activator is involved in the process of neuronal death by oxygen-glucose deprivation. J Cereb Blood Flow Metab 21:631-634.

Nicole O, Docagne F, Ali C, Margaill I, Carmeliet P, MacKenzie ET, Vivien D, Buisson A (2001) The proteolytic activity of tissue plasminogen activator enhances NMDA receptor mediated signaling. Nat Med 7:59-64.

Pawlak R, Rao BS, Melchor JP, Chattarji S, McEwen B, Strickland S (2005) Tissue plasminogen activator and plasminogen mediate stress-induced decline of neuronal and cognitive functions in the mouse hippocampus. Proc Natl Acad Sci U S A 102:18201-18206.

Pulsinelli WA, Brierley JB, Plum F (1982) Temporal profile of neuronal damage in a model of transient forebrain ischemia. Ann Neurol 11:491-498.

Ray SK, Banik NL (2003) Calpain and its involvement in the pathophysiology of CNS injuries and diseases: therapeutic potential of calpain inhibitors for prevention of neurodegeneration. Curr Drug Targets CNS Neurol Disord 2:173-189. 
Seeds NW, Haffke S, Christensen K, Schoonmaker J (1990) Cerebellar granule cell migration involves proteolysis. Adv Exp Med Biol 265:169-178.

Seeds NW, Williams BL, Bickford PC (1995) Tissue plasminogen activator induction in Purkinje neurons after cerebellar motor learning. Science 270:1992-1994.

Tsirka SE (2002) Tissue plasminogen activator as a modulator of neuronal survival and function. Biochem Soc Trans 30:222-225.

Tsirka SE, Gualandris A, Amaral DG, Strickland S (1995) Excitotoxin induced neuronal degeneration and seizures are mediated by TPA. Nature 377:340-344.

Tsirka SE, Rogove AD, Strickland S (1996) Neuronal cell death and TPA. Nature 384:123-124.

Tsubokawa T, Solaroglu I, Yatsushige H, Cahill J, Yata K, Zhang JH (2006) Cathepsin and calpain inhibitor E64d attenuates matrix metalloproteinase- 9 activity after focal cerebral ischemia in rats. Stroke 37:1888-1894.

Tsuji K, Aoki T, Tejima E, Arai K, Lee SR, Atochin DN, Huang PL, Wang X, Montaner J, Lo EH (2005) Tissue plasminogen activator promotes matrix metalloproteinase-9 upregulation after focal cerebral ischemia. Stroke 36:1954-1959.
Wang X, Arai K, Lee SR, Lee S, Tsuji K, Rebeck GW, Lo EH (2003) Lipoprotein receptor-mediated induction of matrix metalloproteinase-9 in human cerebral endothelial cells. Nat Med 9:13131319.

Wang YF, Tsirka SE, Strickland S, Steig PE, Soriano SG, Lipton SA (1998) TPA increases neuronal damage after focal cerebral ischemia in wild type and TPA-deficient mice. Nat Med 4:228-231.

Wu YP, Siao CJ, Lu W, Sung TC, Frohman MA, Milev P, Bugge TH, Degen JL, Levine JM, Margolis RU, Tsirka SE (2000) The tissue plasminogen activator (tPA)/plasmin extracellular proteolytic system regulates seizure-induced hippocampal mossy fiber outgrowth through a proteoglycan substrate. J Cell Biol 148:12951304.

Yamashima T (2000) Implication of cysteine proteases calpain, cathepsin and caspase in ischemic neuronal death of primates. Prog Neurobiol 62:273-295.

Yang G, Kitagawa K, Ohtsuki T, Kuwabara K, Mabuchi T, Yagita Y, Takazawa K, Tanaka S, Yanagihara T, Hori M, Matsumoto M (2000) Regional difference of neuronal vulnerability in the murine hippocampus after transient forebrain ischemia. Brain Res 870: 195-198. 